\title{
Pulmonary Vein Anomalies of Left Atrium - A Descriptive Cadaveric Study
}

\author{
Mani Kathapillai ${ }^{1}$ \\ 1Department of Anatomy, Shri Sathya Sai Medical College and Research Institute, Sri Balaji Vidyapeeth \\ (Deemed to Be University), Ammapettai, Thiruporur, Chengalpattu, Tamil Nadu, India.
}

\section{ABSTRACT}

\section{BACKGROUND}

Catheter extirpation is the currently followed practice in the treatment of atrial contractile dysfunction. This is one of the recent developments in the management of atrial fibrillation. Since the mechanism and progression of the contractility of the atrium is to be assessed through continuous monitoring process, left atrial ablation with the catheter has been found to be an essential treatment option for individuals having arrhythmia especially the atrial abnormal heart rhythm. The technique of atrial ablation needs various solitude markings and fixed landmarks; moreover, the whole process needs conscientious anatomical accomplishment of the chambers of the heart. We wanted to determine the incidence of pulmonary vein absence in cadavers, determine the predominant side of pulmonary vein absence and observe the associated lung lobe anomalies. Most of the available studies are radiological and this study was in cadavers.

\section{METHODS}

This was a descriptive study. 77 adult cadaveric hearts were studied with regard to draining pattern of the pulmonary veins. Moreover, the patterns of fissures of the lungs were included as associated findings.

\section{RESULTS}

3 hearts were associated with the single unilateral pulmonary veins on the left side of the left atrium. Corresponding left lungs were characteristically without fissures both oblique and horizontal.

\section{CONCLUSIONS}

This study highlights the importance of the anatomy of left atrium, importantly about the pulmonary veins since it is associated with pulmonary hypertension, haemoptysis etc. Moreover, it will be a useful guide in cardiac arrhythmia for the catheter ablation, pneumonectomy, etc.

\section{KEY WORDS}

Left Atrium, Pulmonary Vein, Cardiac Arrhythmia, Catheter Ablation Pneumonectomy

\author{
Corresponding Author: \\ Dr. Mani Kathapillai, \\ Department of Anatomy, \\ Shri Sathya Sai Medical College and \\ Research Institute, Sri Balaji Vidyapeeth \\ (Deemed to Be University), \\ Ammapettai, Thiruporur, \\ Chengalpattu- 603108, \\ Tamil Nadu, India. \\ E-mail: kathapillaimani@gmail.com
}

DOI: $10.14260 / j e m d s / 2021 / 42$

How to Cite This Article: Kathapillai M. Pulmonary vein anomalies of left atrium - a descriptive cadaveric study.J Evolution Med Dent Sci 2021;10(04):194198, DOI: 10.14260/jemds/2021/42

Submission 25-09-2020,

Peer Review 26-11-2020,

Acceptance 03-12-2020,

Published 25-01-2021.

Copyright (C) 2021 Mani Kathapillai. This is an open access article distributed under Creative Commons Attribution License [Attribution 4.0 International (CC BY 4.0)] 


\section{BACKGROUND}

Two lungs of the human, drain the oxygen rich blood into the left atrium of the heart located in the middle mediastinum, through four number of individual openings on the "sides". Abnormalities of the pulmonary opening number and the pattern of drainage were frequently noted in the literature nevertheless given little importance since they exhibit subtle clinical signs and symptoms. Meticulous understanding of the abnormalities of the pulmonary ostial (PO) opening is pertinent for the programming of various surgical procedures like replacements of the valves of the heart, lobectomy of the lungs etc. This anatomical understanding stays as a key factor in performing radiofrequency ablation in patients suffering from atrial fibrillation. Cadaveric investigations and autopsy studies are the deserving records for these research, but such materials are available in least "amount". ${ }^{2}$ Ostia of the pulmonary vein number anomalies at the sides of each left atrial chamber of the hearts were envisaged as a rare "entity". 3 Substantiating evidences available in the literature search are either case reports, case series and radiological "investigations".4-8 Catheter extirpation is the currently followed practice in the treatment of atrial contractile dysfunction. This is one of the recent decade developments in the management of atrial fibrillation. Since the mechanism and progression of the contractility of the atrium is to be assessed through continuous monitoring process, left atrial ablation with the catheter has found an essential treatment option for the individuals having arrhythmia especially the atrial abnormal heart rhythm. The technique of the atrial ablation needs various solitude markings and fixed landmarks are being utilised, moreover the whole process needs conscientious anatomical accomplishment of the chambers of the heart. Our aim is to highlight the prerequisites with respect to the arrangement of pulmonary ostia of the left atrium. In this manuscript, we relearn the placement of the pulmonary openings of the left atrium and related anomalies of the neighbouring structures of respiratory as well as cardiovascular "system". 9

Left atrial walls of the heart could be described as possessing walls made up of muscle fibres of fine texture. The walls are namely front, back, upper, sinistral and also septal. The walls of the left atrium are thin, muscular and could be described by "McAlpine". 10 These findings correlates with the placement of the heart in the middle mediastinum of the chest cavity. The orientation being oblique with its base facing backwards anterior to the oesophagus, descending thoracic aorta etc, for which he used a term known as attitudinal. Moreover, this is a most widely accepted terminology in the field of interventional "cardiology".11 Most commonly, the upper right pulmonary vein traverses posterior to the meeting point between the right atrium and the superior vena cava. But the lower vein of the pulmonary system courses posterior to the intercaval region. The orifices of the right pulmonary veins are nearly closer to the orientation of the interatrial septum of the heart. Developments in techniques of radiological investigations during the recent years paved the way to diagnose ample number of positive cases with anomalous number of venous openings into the left atrial chamber of the heart and its "arrangements".12 Novelty of the study was to know the patterns of variations of the venous openings of the left atrium and the number and absence of the pulmonary vein in Indian population since most of the available studies are radiological and this study was one among in cadavers.

\section{Objectives}

1. To determine the incidence of different numbers of pulmonary vein openings or its absence in cadavers.

2. To determine the predominant side of pulmonary vein openings or its absence

3. To observe the associated lung lobe anomalies.

\section{METHODS}

The descriptive cadaveric study was conducted at Shri Sathya Sai Medical College and Research Institute, Sri Balaji Vidyapeeth, Deemed to Be University, Kanchipuram, Tamil Nadu and Rajah Muthiah Medical College and Hospital, Annamalai University Chidambaram, Tamil Nadu. The period of study was from April 2009 to October 2020, over a period of 11 years. The total number of heart specimens included in this study was 77. It was a descriptive study of the pulmonary vein openings into the left atrium of the hearts and associated gross anatomical anomalies of the lungs. The study population was formalin fixed hearts and their corresponding lungs of the affected hearts from the two institutes. Ethical committee approval was obtained from the institute research committee with due application and protocol.

Sample size calculation was done with the previous study prevalence of $26 \%$ i.e. $4 * 26 * 74 / 10 * 10$ equals to 77 ; Kauer et al 2017. Inclusion criteria were heart and lung specimens with intact walls, borders and surfaces. Lungs and hearts without intact walls and borders and surfaces were excluded from this study. Presence or absence and the number of openings of the pulmonary veins into the left atrium and pattern and number of lobes of the lungs were meticulously studied and photographed digitally.

Data analysis was done using descriptive type of data analysis.

\section{RESULTS}

Within the 77 hearts there were anomalous pulmonary vein openings in 3 hearts (3.9\%). Among the 3 hearts with single pulmonary vein, on the left side, there were 3 and with two or more pulmonary veins in the right side. Among the 3 lungs associated with the anomalous pulmonary vein draining into the hearts, they were characteristically without fissures or incomplete fissures.

\begin{tabular}{|ccc|}
\hline Sl. No. & Pulmonary Vein Variants & $\mathbf{\%}$ \\
1 & Separate right middle lobe pulmonary & $19-23$ \\
2 & Joint pulmonary vein & $2.4-25$ \\
3 & Anomalous pulmonary venous return & $<1$ \\
\hline \multicolumn{3}{|c|}{ Table 1. Paul Cronin et al 2004 } \\
\hline
\end{tabular}




\begin{tabular}{|c|c|c|c|c|c|c|c|}
\hline $\begin{array}{l}\text { Sl. } \\
\text { No. }\end{array}$ & Author & $\begin{array}{c}\text { No. } \\
\text { of } \\
\text { Cases }\end{array}$ & $\begin{array}{l}\text { Associated } \\
\text { Conditions }\end{array}$ & Side & Year & Sex & Age \\
\hline 1 & Benfield et al & 1 & None & $\mathrm{L}$ & 1971 & $\mathrm{~F}$ & 67 \\
\hline 2 & Treatheway et al & 1 & None & L & 1974 & M & 38 \\
\hline 3 & $\begin{array}{l}\text { Ben Menschem } \\
\text { et al }\end{array}$ & 2 & None & $\mathrm{R}$ & 1975 & $\mathrm{~F}$ & 50,53 \\
\hline 4 & Twersky et al & 1 & None & $\mathrm{L}$ & 1976 & M & 51 \\
\hline 5 & Kozuka et al & 1 & $\begin{array}{l}\text { Atelectasis of middle } \\
\text { lobe }\end{array}$ & $\mathrm{R}$ & 1968 & $\mathrm{~F}$ & 6 \\
\hline 6 & Brokard et al & 1 & None & $\mathrm{L}$ & 1970 & M & 37 \\
\hline 7 & Bartram et al & 1 & None & $\mathrm{R}$ & 1971 & M & 30 \\
\hline 8 & Morgan et al & 1 & $\begin{array}{l}\text { Hypoplastic R lung, } \\
\text { Heart dextroposition }\end{array}$ & $\mathrm{R}$ & 1971 & M & 22 \\
\hline 9 & Papamichael et al & 1 & $\begin{array}{c}\text { RPA hypoplasia, } \mathrm{R} \\
\text { diaphragm eventration, } \\
\text { R lung bronchiectasis }\end{array}$ & $\mathrm{R}$ & 1972 & M & 39 \\
\hline 10 & Stenstrom et al & 1 & $\mathrm{R}$ lower lobe pneumonia & $\mathrm{R}$ & 1942 & M & $\begin{array}{c}2 \\
\text { months }\end{array}$ \\
\hline 11 & Belott et al & 1 & PAPVR & $\mathrm{L}$ & 1977 & M & 19 \\
\hline 12 & $\begin{array}{c}\text { Valdez Davila et } \\
\text { al }\end{array}$ & 1 & $\begin{array}{l}\text { R lung hypoplasia, } \mathrm{R} \\
\text { bronchogenic } \\
\text { pulmonary cyst }\end{array}$ & $\mathrm{R}$ & 1978 & M & 20 \\
\hline 13 & Hasuo et al & 2 & None, PAPVR & $\mathrm{R}$ & 1981 & M & 22,57 \\
\hline 14 & $\begin{array}{l}\text { Ben Menachem } \\
\text { et al }\end{array}$ & 2 & None & $\mathrm{R}$ & 1975 & $\mathrm{~F}$ & 50,53 \\
\hline 15 & Rey et al & 1 & $\begin{array}{c}\text { R Lung \&RPA } \\
\text { hypoplasia, } \\
\text { dextroposition of heart }\end{array}$ & $\mathrm{R}$ & 1985 & M & 9 \\
\hline 16 & Present study & 3 & $\begin{array}{l}\text { Absence of fissures } \\
\text { (both oblique \& } \\
\text { horizontal }\end{array}$ & $\mathrm{L}$ & 2020 & $2 \mathrm{M}, \mathrm{F}$ & Adults \\
\hline \multicolumn{8}{|c|}{ nomalous Pulmonary Vein, 1} \\
\hline
\end{tabular}

\section{DISCUSSION}

Atresia of the veins of the left atrium of a single lateral side was few and far between among the birth defect occurrence also it was associated with considerably increased disease and death "rate".13,14 Identifying the anomalies of the veins of the left atrium was done in the early years of the patient and seldom done till he attains his "adulthood". ${ }^{15}$ Quiet a good number of incidences were there, usually majority of cases were thought to be since birth, because of the non-incorporation of the united pulmonary vein with that of the left "atrium".16 Moreover the above said anomaly could be associated with blockage of the veins and subsequent obstruction of the main artery itself and also the branches and prevalence of limited connection in-between the pulmonary and systemic venous "return". ${ }^{17}$ This type of pulmonary venous anomalies are often associated with defective septum of the ventricles and persistence of the connection between the left branch of the pulmonary artery and the under surface of the arch of the aorta namely the patent ductus arteriosus. This may amount to $50 \%$ as per the literature evidences. Obstruction of the pulmonary venous system may be an acquired phenomenon in the hearts, the reason being the inflammation of the involved vessel "lumen". ${ }^{18}$

Signs and symptoms of the pulmonary venous anomalies could be repeated infections of the pulmonary system, difficulty in breathing, coughing out blood, and workout "intolerance". 19 The positive roentgenogram of the chest of the pulmonary venous anomaly includes, same side pulmonary mal-development, mediastinal move towards the side of involvement and infiltrative interstitial involvement of the ipsi-lateral lower lobe of the affected pulmonale. Even-though the findings were clear cut to diagnose pulmonary venous anomalies they were seldom useful to diagnose in case of young individuals and newly born babies that too when pulmonary findings were not present. Complications of these anomalies were coughing out blood, supposed to be the major threat. The cause of this scenario was said to be increased pressure in the pulmonary system and the corresponding increase in the pressure of the vessels exclusively the veins of the bronchus and it breakage. The relationship of the dilatations and tortuosity to the blockage of the veins of the pulmonary system has rarely been "described". ${ }^{20}$ The explanation for the above said mechanism could be elaborated as there was enormous amount of pressure increase in the pulmonary system there by natural compensatory mechanism came into play with diversion of pulmonary blood flow into the systemic side. In our case, being a cadaveric study there was associated non-segmentation of the lungs.

Literature evidences categorise that there was incidence of reduced development of the bronchus of the middle lobe of the right lung. Moreover there may be an associated involvement of the upper segment of the superior lobe of the right lung. As a matter of highlight, in our study only the left sided lungs showed abnormal findings with respect to the size. In addition to the above finding, there was absence of both the oblique and horizontal fissures in the three of the left lungs. Moreover single pulmonary vein was found in all the three hearts' left lateral side of the left atrium peculiarly. This observation was primarily disclosed by Kozuka and "Nosaki".21 The specific name for this anomaly was named as unilateral single pulmonary vein (UPV). An anomalous UPV was a solitary vein which drains into the same side left atrium after collecting blood from all the veins of the pulmonary system. The above said defective pattern of the UPA could be seen with an anomaly known as the hypo genetic lung (scimitar) syndrome. It was advised to have the above said condition as a differential diagnosis, when the patient was having single pulmonary vein in one side of the heart's left atrium, associated with repeated respiratory infections, pulmonary hypertension and haemoptysis.

Literature searches enumerated patterns and details of the anomalous pulmonary veins were "available".21-24 Rey et al. tabulated 17 cases (Table 2) of the details including the age, sex, year, side, associated conditions, number of cases, author about the pulmonary vein which was lone, present on one side that frequently found on the right side of the left atrium. In our study the most commonly affected side was left side of the left atrium. Our study also was significant as the above study where three of the single pulmonary vein entered the left atrium's left lateral aspect. Diameter of the anomalous unilateral single pulmonary vein was $21.5 \mathrm{~mm}$ maximum. Moreover it was in the literature that the diameter of the single pulmonary veins used to have maximum diameter compared to the other veins of the opposite side. In our study this was proved on the higher stand that the diameter of the anomalous pulmonary venous diameter was at its maximum in contrast to the right lateral left atrial veins.

Abnormalities of the veins of the pulmonary system were usually congenital pulmonary venous anomalies and were related to the complex development of the venous system. During the embryonic development, venous blood of the pulmonary system drains into the systemic venous system's primordium through the plexus of the splanchnic system which also included the cardinal venous system as well as the vitelline-umbilical venous system. There developed two evaginations one at the caudal end of the sinoatrial region and 
another one at the cranial end of the sinoatrial region of the developing heart tube. Both the caudal and cranial evaginations from the sinoatrial region move towards the developing lung bud primordium. Subsequently there was retrogression of the caudal "evagination". ${ }^{25}$ The cranial part of the evaginated sinoatrial part progressed to develop into the common pulmonary vein. At about 28 - 30 days of gestation the pulmonary common vein intermingles with the venous plexus of the pulmonary system. In due course the fully developed pulmonary systems veins were ready to get isolated from the communications with the prime splanchnic venous system "plexus". ${ }^{25,26}$ At the end of 30 - 32 days of gestation, splanchnic plexus connections of the pulmonary system was stopped and the common pulmonary vein gets incorporated into the wall of the left atrium. To start with two pulmonary veins and further division of the two into four branches, finally as the four pulmonary veins separately draining into the left atrial "chamber". ${ }^{26,27}$ Pulmonary common venous incomplete incorporation into the heart chamber's left atrium leads to a condition known as the pre-atrial accessory persistent chamber called as "cortriatriatum".27,28,29 In this investigation no such deformity was found in the hearts.

Anatomy of the pulmonary vein was more variable than anatomy of the pulmonary artery. Most commonly pulmonary developmental venous anomalies were prevalent. Literature evident anomalous pulmonary veins were tabulated. (Table 1) included a single anomalous pulmonary vein (PVA) or common right or left pulmonary vein in $2.4-25 \%$ of "individuals"10,12 (Table 1). Most frequently reported anomaly was the single left common pulmonary vein opening with maximum diameter rather than a common single right pulmonary vein. In our experience with 77 patients, we have not yet come across a common unilateral single right vein. It was only on the left lateral margin of the left atrium in three hearts we could be able to locate the lone openings of the pulmonary veins. Literature evidences said that there was reported incidence of when it was present a common pulmonary vein trunk had a significantly larger diameter than the other pulmonary veins. In this investigation also we found the maximum diameter of $21.5 \mathrm{~mm}$ maximum of the left pulmonary vein opening. In our study there was an associated absent fissure of the left lungs.

\section{CONCLUSIONS}

Atresia or absence or reduced openings of pulmonary veins into the left atrium of heart was a few and far between incidence. The above said conditions were usually associated with the developmental deformities of the hearts. Lone atresia or reduced number of pulmonary venous left atrial ostia were extremely thin on the ground. Repeated attacks of respiratory infections amenable to common modality of medical management, high and refractile pulmonary hypertension etc combined with adequate and appropriate investigative modules would of pertinent additive during the earlier diagnosis and treatment. Pulmonary venous narrowing could be assessed preoperatively with the help of latest diagnostic modalities such as magnetic resonance angiography and 124 slice computerised tomogram said to be fairly non-invasive in nature.
Congenital unilateral single pulmonary absent vein is rare and seldom diagnosed in infancy. Chances of detecting single pulmonary vein absence is higher when there is a pulmonary hypo development associated with infiltrative pattern of interstitium of the lung parenchyma. Cardiac catheterisation is the gold standard for a definite diagnosis allowing one to confirm whether the pulmonary veins are atretic or stenotic and is also useful in providing assessment and eventual interventional treatment of the potential expected complications. In symptomatic cases, pneumonectomy is indicated as a vital measure to bring down mortality, critically related to haemoptysis and pulmonary hypertension. In case of cases without symptoms, the alternative management is supposed to be the non-invasive mode. It includes regular, periodic meticulous follow-up of the cases which weighs on a drastic scale, by abstaining from the surgical line of management, associated with uncertain complications which is a boon for the group of children who are fairly younger.

Paroxysmal atrial fibrillation could be adequately managed nowadays by radiofrequency ablation by electric isolation of the veins of the pulmonary system by the application of radiofrequency energy at the venoatrial junction in a new technique. Since atrial fibrillation is the commonest of all the cardiac arrhythmias, there seems to be escalated number of centres performing ablations. The core details needed noninvasively earlier to the procedure, for an interventional cardiologist was the number, location, and size of the pulmonary veins and pulmonary vein branching anomalies, and would be used to select the catheter size for the intervention method. Radiofrequency ablation technique time would be reduced when pre-procedural mapping has been meticulous. Survey of the pulmonary veins is of great use to assess the blocked, clotted vessels at the end of the catheter ablation. Therefore, radiologists need to be familiar about how to perform and interpret pulmonary vein mapping examinations, whether done with CT or magnetic resonance imaging (MRI). A thorough knowledge and understanding of normal as well as abnormal anatomy like anomalous pulmonary vein anatomy, marking of areas and taking measurements are important and expected for safe and successful interventions.

Data sharing statement provided by the author is available with the full text of this article at jemds.com.

Financial or other competing interests: None.

Disclosure form provided by the author are available with the full text of this article at jemds.com.

\section{REFERENCES}

[1] Gray H, Carter HV. Heart and great vessels. In: Susan Standring, edr. Gray's Anatomy. The Anatomical basis of clinical practice. 39th edn. Churchil Livingstone Elsevier 2000: p. 1027.

[2] Marom EM, Herndon JE, Kim YH, et al. Variations in pulmonary venous drainage to the left atrium: Implications for radiofrequency ablation. Radiology 2004;230(3):824-9.

[3] Alfke H, Wagner HJ, Klose KJ. A case of an anomalous pulmonary vein of the right middle lobe. Cardiovasc Intervent Radiol 1995;18(6):406-9. 
[4] Collins DR, Shea PM, Vieweg WV. Idiopathic prominence of pulmonary veins on chest X-ray. Angiology 1982;33(9):613-6.

[5] Benfield JR, Gots RE, Mills D. Anomalous single left pulmonary vein mimicking a parenchymal nodule. Chest 1971;59(1):101-3.

[6] Hasuo K, Numaguchi Y, Kishikawa T, et al. Anomalous unilateral single pulmonary vein mimicking pulmonary varices. Chest 1981;79(5):602-4.

[7] Tretheway DG, Francis GS, MacNeil DJ, et al. Single left pulmonary vein with normal pulmonary venous drainage: a roentgenographic curiosity. Am J Cardiol 1974;34(2):237-9.

[8] Rey C, Vaksmann G, Francart C. Anomalous unilateral single pulmonary vein mimicking partial anomalous pulmonary venous return. Cathet Cardiovasc Diagn 1986;12(5):330-3.

[9] Ho SY, Sanchez-Quintana D, Cabrera JA, et al. Anatomy of the left atrium: implications for radiofrequency ablation of atrial fibrillation. J Cardiovasc Electrophysiol 1999;10(11):1525-33.

[10] McAlpine WA. Heart and Coronary Arteries. Berlin/ Heidelberg: Springer- Verlag 1975: p. 58-9.

[11] Farre J, Anderson RH, Cabrera JA, et al. Cardiac anatomy for the interventional arrhythmologist: I. terminology and fluoroscopic proj- ections. Pacing Clin Electrophysiol 2010;33(4):497-507.

[12] Pappone C, Oreto G, Rosanio S, et al. Atrial electroanatomic remodelling after circumferential radiofrequency pulmonary vein ablation: efficacy of an ana-tomic approach in a large cohort of patients with atrial fibrillation. Circulation 2001;104(21):2539-44.

[13] Beerman LB, Oh KS, Park SC, et al. Unilateral pulmonary vein atresia: clinical and radiographic spectrum. Pediatr Cardiol 1983;4(2):105-12.

[14] Cullen S, Deasy PF, Tempany E, et al. Isolated pulmonary vein atresia. Br Heart J 1990;63(6):350-4.

[15] Heyneman LE, Nolan RL, Harrison JK, et al. Congenital unilateral pulmonary vein atresia: radiologic findings in three adult patients. Am J Roentgenol 2001;177(3):681-5.

[16] Ussia GP, Marasini M, Rimini A, et al. Atresia of right pulmonary veins with intact atrial septum and major aorto-pulmonary collateral treated with percutaneous stent implantation and embolization. J Intervent Cardiol 2004;17(3):183-7.
[17] Edwards JE. Congenital stenosis of pulmonary veins. Pathologic and developmental considerations. Lab Invest 1960;9:46-66.

[18] Pourmoghadam KK, Moore JW, Khan M, et al. Congenital unilateral pulmonary venous atresia: definitive diagnosis and treatment. Pediatr Cardiol 2003;24(1):73-9.

[19] Nasrallah AT, Mullins CE, Singer D, et al. Unilateral pulmonary vein atresia: diagnosis and treatment. Am J Cardiol 1975;36(7):969-73.

[20] Wiebe S, Maclusky I, Manson D, et al. Hemoptysis: a rare cause can be related to a bronchial varix due to pulmonary venous obstruction. Pediatr Radiol 2003;33(12):884-6.

[21] Kozuka T, Nosaki T. A pulmonary vein anomaly:unusual connection and tortuosity of the rightlower lobe vein. Br J Radiol 1968;41(483):232-4

[22] Hidvegi RS, Lapin J. Anomalous bilateral singlepulmonary vein demonstrated by 3-dimensional reconstruction of helical computed tomographicangiography: case report. Can Assoc Radiol J 1998;49(4):262-5.

[23] Goodman LR, Jamshidi A, Hipona FA. Meandering right pulmonary vein simulating the scimitar syndrome. Chest 1972;62(4):510-12.

[24] Gilkeson RC, Haaga JR, Ciancibello LM. Anomalous unilateral single pulmonary vein: multidetector CT findings. AJR Am J Roentgenol 2000;175(5):1464-5.

[25] Zylak CJ, Eyler WR, Spizarny DL, et al. Developmental lung anomalies in the adult: radiologic-pathologic correlation. RadioGraphics 2002;22 [special issue]:S25-S43.

[26] Neill CA. Development of the pulmonary veins with reference to the embryology of anomalies of pulmonary venous return. Pediatrics 1956;18(6):880-7.

[27] Mohiuddin SM, Levin HS, Runco V, et al. Anomalous pulmonary venous drainage. A common trunk emptying into the left atrium and inferior vena cava. Circulation 1966;34(1):46-51.

[28] Nakib A, Moller JH, Kanjuh VI, et al. Anomalies of the pulmonary veins. Am J Cardiol 1967;20(1):77-90.

[29] Becu LM, Tauxe WN, Du Shane JW, et al. Anomalous connection of pulmonary veins withnormal pulmonary venous drainage: report of caseassociated with pulmonary venous stenosis and cortriatriatum. AMA Arch Pathol 1955;59(4):463-70. 